\title{
Erratum to: Selective detection of alkaloids in MALDI-TOF: the introduction of a novel matrix molecule
}

\author{
Andreas Schinkovitz • Ghislain Tsague Kenfack • \\ Denis Seraphin • Eric Levillain • Maryléne Dias • \\ Pascal Richomme
}

Received: 10 May 2012 / Accepted: 10 May 2012 / Published online: 3 June 2012

(C) Springer-Verlag 2012

\section{Erratum to: Anal Bioanal Chem}

DOI 10.1007/s00216-012-5958-y

The authors would like to call readers' attention to the fact that in the published article the molecular formulas in Table 1 were wrongly assigned to the compound's names. Please find the correct Table 1 below:

The online version of the original article can be found at http:/ dx.doi.org/10.1007/s00216-012-5958-y.

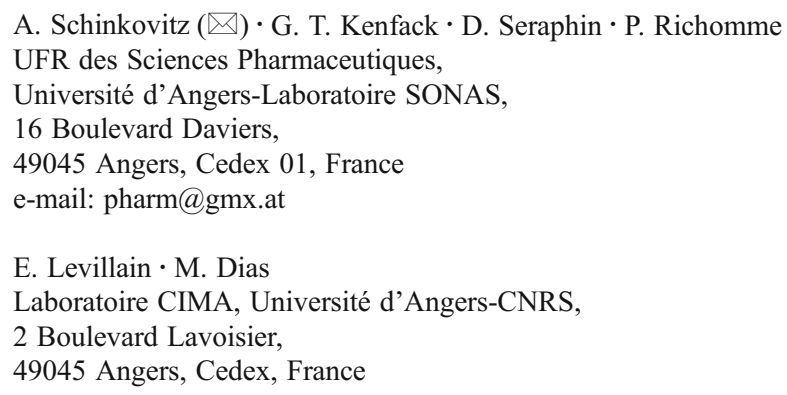




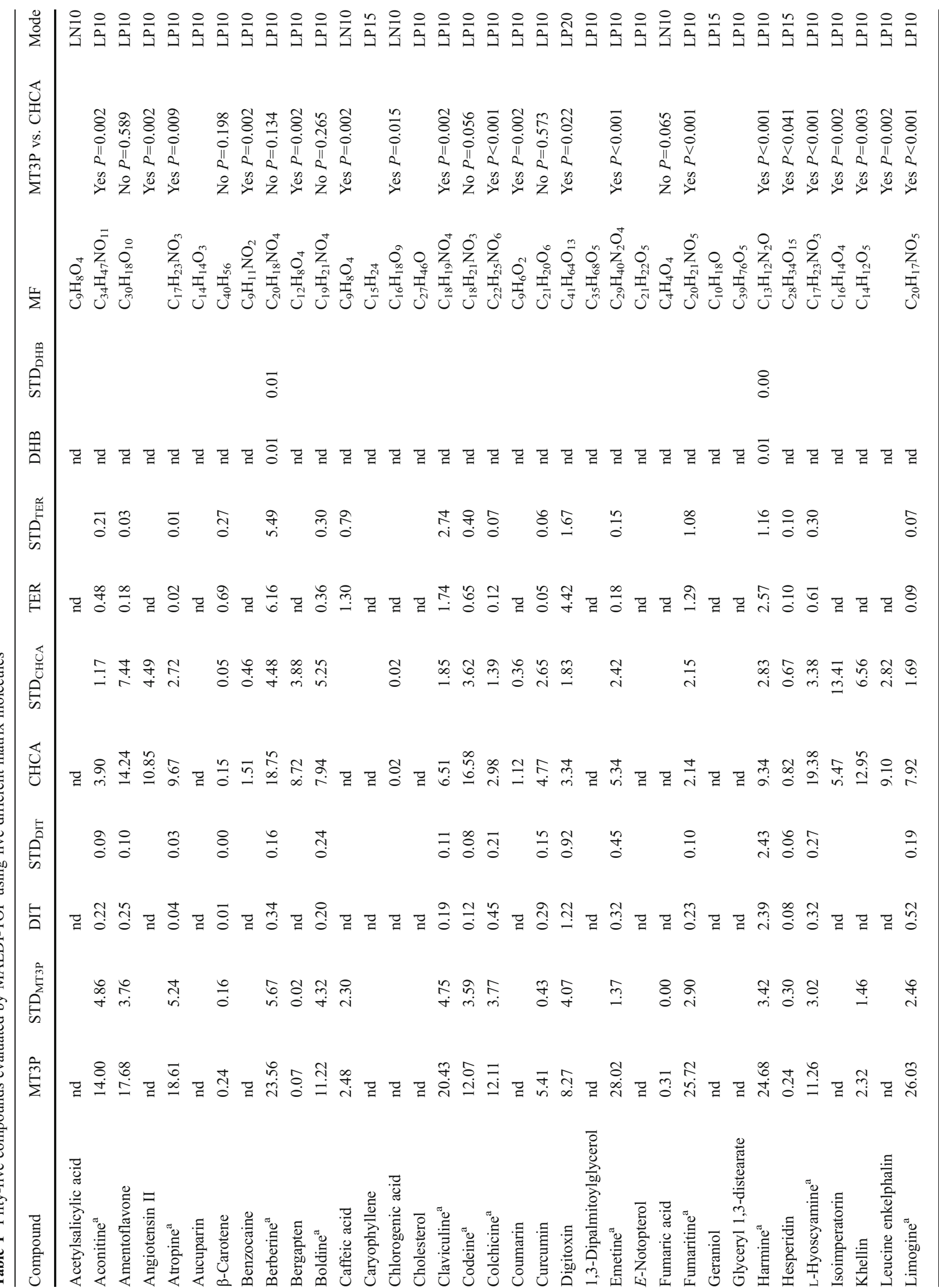




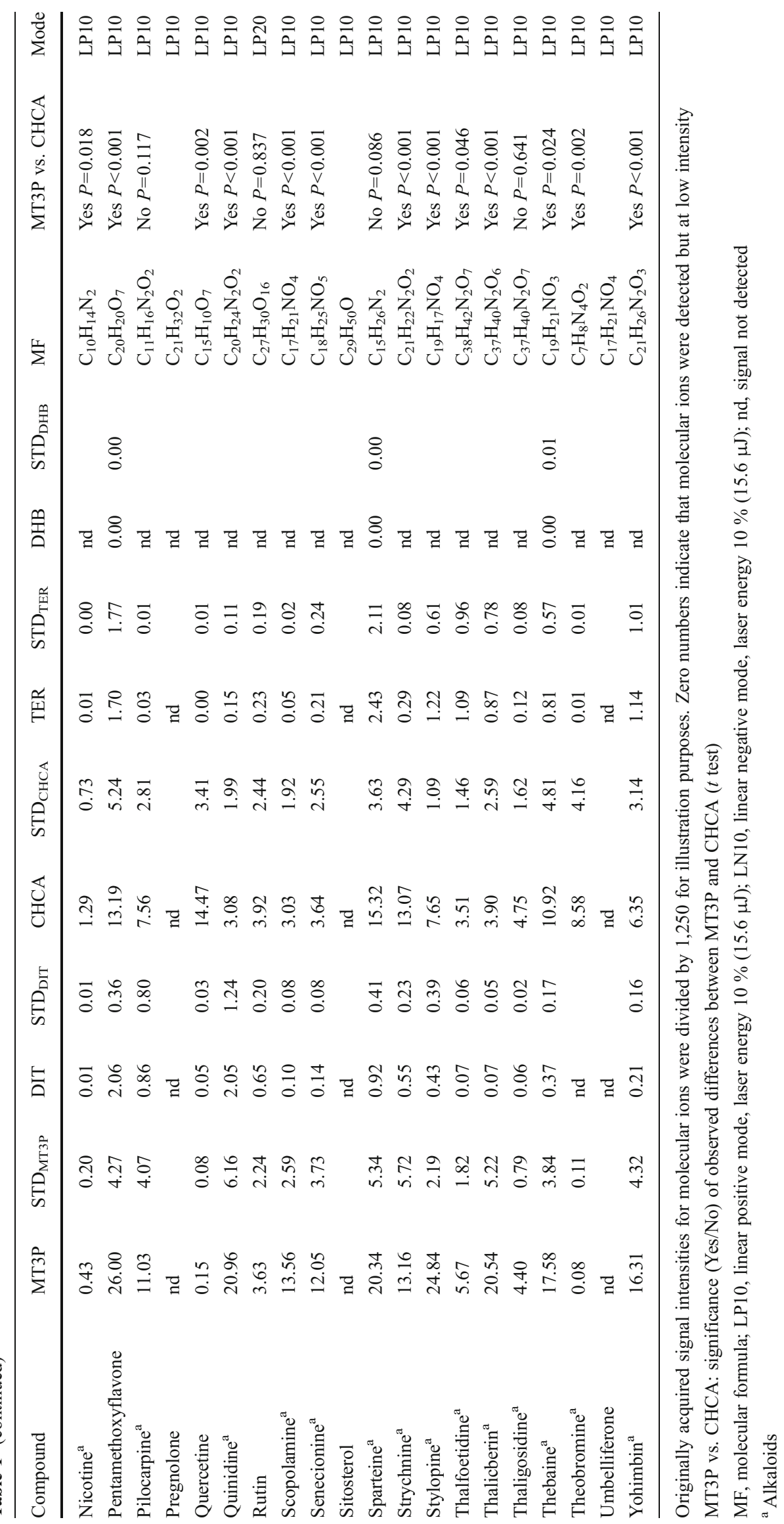

